\title{
Modulating the Emission Intensity of Poly-(9,9-bis(6'-N,N,N-trimethylammonium)hexyl)-Fluorene Phenylene) Bromide Through Interaction with Sodium Alkylsulfonate Surfactants
}

\author{
María Monteserín, ${ }^{\dagger}$ Hugh D. Burrows, ${ }^{*}, *$ Artur J. M. Valente,$‡$ Victor M. M. Lobo,, \\ Ricardo Mallavia, ${ }^{\S}$ María J. Tapia, ${ }^{*}{ }^{\dagger}$ Iñigo X. García-Zubiri, ${ }^{\dagger}$ Roberto E. Di Paolo," and \\ Antonio L. Maçanita" \\ Departamento de Química, Universidad de Burgos, Plaza Misael Bañuelos, Burgos 09001, Spain, \\ Departamento de Química, Universidade de Coimbra, 3004-535 Coimbra, Portugal, Instituto de Biología \\ Molecular y Celular, Universidad Miguel Hernández, Elche 03202, Alicante, Spain, and Departamento de \\ Engenharia Química e Biologica, Instituto Superior Técnico (IST), Avenida Rovisco Pais, P1049-001, \\ Lisboa, Portugal
}

Received: May 30, 2007; In Final Form: September 1, 2007

\begin{abstract}
The interaction between the cationic HTMA-PFP (Poly-(9,9-bis $\left(6^{\prime}-N, N, N\right.$-trimethylammonium)hexyl-fluorene phenylene) bromide) and oppositely charged sodium $n$-alkyl sulfonate surfactants of different chain lengths has been studied in DMSO-water solutions (4\% v/v) by UV-visible absorption, fluorescence spectroscopy, fluorescence lifetimes, electrical conductivity, and ${ }^{1} \mathrm{H}$ NMR spectroscopy. Polymer-surfactant interactions lead to complex spectroscopic behaviors which depends on surfactant concentration. At low surfactant concentrations, the observed strong static fluorescence quenching of fluorescence seems to be associated with formation of aggregates between polymer chains neutralized through interaction with surfactants. This is supported by conductivity and by analysis of absorption spectra deconvoluted at each surfactant concentration using an adapted iterative method. In contrast, above the surfactant critical micelle concentration, there is a strong fluorescence enhancement, leading in some cases to higher intensities than in the absence of surfactants. This is attributed to the transformation of the initially formed aggregates into some new aggregate species involving surfactant and polymer. These changes in HTMA-PFP fluorescence as a function of $n$-alkyl sulfonate concentration are important for the general understanding of polymer-surfactant interactions, and the aggregates formed may be important as novel systems for applications of these conjugated polyelectrolytes.
\end{abstract}

\section{Introduction}

Conjugated polyelectrolytes are conjugated polymers containing charged groups and are finding applications as chemical and biological sensors, ${ }^{1-9}$ in addition to their potential in molecular electronics for charge injection and transport. ${ }^{10}$ Moreover, they may undergo self-assembly with oppositely charged species, such as surfactants, to build up complex multilayer structures with interesting materials properties. ${ }^{11}$ They are also relevant for the development of high resolution inkjet printing $^{12}$ where there is a clear need for good water-based formulations of conjugated polymers.

A particularly important group of conjugated polyelectrolytes involves fluorene based systems, ${ }^{3,4,13}$ which have the advantages of high fluorescence quantum yields and blue emission, ${ }^{14}$ making them very suitable for use in areas such as Förster resonance energy transfer (FRET). In addition, the rigid polyfluorene backbone linked to the flexible side chains induces interesting aggregation behavior, ${ }^{3 \mathrm{f}, 10 \mathrm{~d}, 13 \mathrm{a}, \mathrm{c}, \mathrm{d}, \mathrm{g}}$ which has proved particularly valuable for studying interactions with nucleotides, nucleic acids, and peptide nucleic acids. Methodologies have

* Corresponding authors. E-mail: mjtapia@ubu.es. Phone: +34 947258061. Fax: (+34) 94728831 (M.J.T.) E-mail: burrows@ci.uc.pt. Phone: +351 239854482. Fax: (+351) 239827703 (H.D.B.).

$\dagger$ Universidad de Burgos.

$\doteqdot$ Universidade de Coimbra.

§ Universidad Miguel Hernández.

"Instituto Superior Técnico. been developed for DNA sensing with cationic fluorene based copolymers. ${ }^{3 \mathrm{~b}, \mathrm{f}, \mathrm{h}, \mathrm{i}, 4 \mathrm{a}}$

Various behaviors are observed when surfactants interact with conjugated polyelectrolytes in water. Initial studies by Whitten and co-workers ${ }^{1}$ involved the relatively flexible anionic conjugated polymer poly(2,5-methoxy-propyloxysulfonate phenylene vinylene) (MPS-PPV), where the fluorescence was dramatically enhanced in the presence of oppositely charged surfactants. ${ }^{1 b}$ In addition, surfactant complexation favored electron-transfer quenching by neutral molecules, such as nitroaromatics ${ }^{1 \mathrm{c}}$ but inhibited quenching by cationic quenchers such as methylviologen. There are a number of other reports of dramatic changes of fluorescence of conjugated polyelectrolytes with surfactants, ${ }^{7 a, 13,15}$ and Bunz has introduced the concept of surfactochromaticity ${ }^{7 a}$ to describe this. With oppositely charged surfactants, both fluorescence enhancement ${ }^{1 \mathrm{a}, 13 \mathrm{e}, 15}$ and quenching ${ }^{13 \mathrm{~b}}$ have been observed. In the latter case, involving an anionic fluorene-phenylene based conjugated polyelectrolyte and single chain cationic surfactants, it was suggested that formation of large polyelectrolyte-surfactant aggregates may be responsible. We complement this work with a study of the interaction of the related cationic poly(9,9-bis $\left(6^{\prime}-N, N, N\right.$-trimethylammonium)hexyl-fluorene phenylene) bromide, HTMA-PFP, copolymer with negatively charged sulfonate and sulfate surfactants (Figure $1)$. The effects of the surfactant concentration, $n$-alkyl chain length and the surfactant head group on absorption and emission 


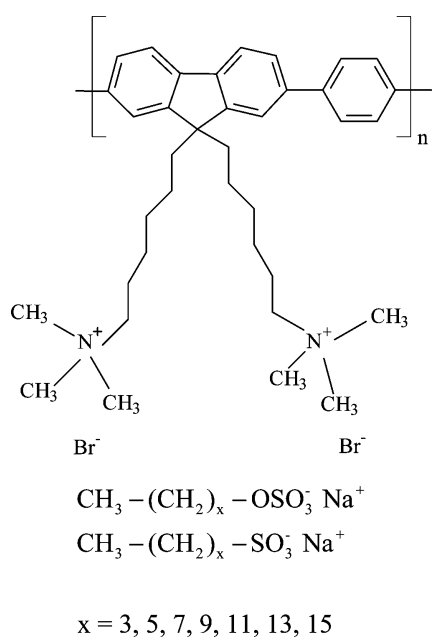

Figure 1. HTMA-PFP and $n$-alkyl sulfate/sulfonate structures.

spectra, and electrical conductance in solution are studied to see how these interactions can modulate the optical and conductivity properties of this polymer in solution. In addition, ${ }^{1} \mathrm{H}$ NMR spectroscopy has been used to characterize the solution behavior. It is worthy to note that the copolymer studied has a significantly higher molecular weight than those used in previous reports, which may facilitate aggregation.

\section{Experimental Section}

Reagents and Solution Preparation. The cationic conjugated polyeletrolyte poly-(9,9-bis( $6^{\prime}-N, N, N$-trimethylammonium)hexyl-fluorene phenylene) bromide (HTMA-PFP, $\overline{M_{n}}=24315$ $\mathrm{g} \mathrm{mol}^{-1}$, repeat unit molecular weight, $\left.694.71 \mathrm{~g} \mathrm{~mol}^{-1}\right)$ was obtained by treating the neutral polymer poly(9,9-bis $\left(6^{\prime}\right.$-hexyl bromide)-fluorene phenylene), synthesized by Suzuki coupling reaction with $\mathrm{Pd}(\mathrm{II})$ as catalyst, with gas-phase trimethylamine following a procedure described elsewhere. ${ }^{3 \mathrm{~g}}$

The polymer shows negligible solubility in water but dissolves in dimethyl sulfoxide-water mixtures. The effect of cosolvents on the aggregation and solubility behavior of conjugated polyelectrolytes is discussed in detail elsewhere. ${ }^{13 g}$ Stock polymer solutions with concentrations around $9.6 \times 10^{-2} \mathrm{~g} / \mathrm{L}$ $\left(1.38 \times 10^{-4} \mathrm{~mol} / \mathrm{L}\right.$ in repeat units $)$ were prepared in dimethyl sulfoxide (DMSO, Aldrich, spectrophotometric grade) by continuous stirring overnight. Aliquots were diluted with Millipore-Q water to produce solutions for the spectroscopic and conductivity measurements with polymer concentrations around $5.5 \times 10^{-6} \mathrm{M}$ (repeat units) in $4 \%(\mathrm{v} / \mathrm{v}) \mathrm{DMSO}-$ water.

Sodium alkyl sulfonate surfactants with different chain lengths were purchased and used without further treatment $\left(\mathrm{CH}_{3}-\right.$ $\left(\mathrm{CH}_{2}\right)_{n}-\mathrm{SO}_{3} \mathrm{Na}$ : butyl (SBSu, Fluka), hexyl (SHSu, Aldrich), octyl (SOSu, Aldrich), decyl (SDeSu, Sigma), dodecyl (SDSu, Fluka), tetradecyl (STSu, Fluka), and hexadecyl (SHeSu, Fluka)). To compare the effect of the anionic surfactant head groups, a series of sulfate surfactants $\left(\mathrm{CH}_{3}-\left(\mathrm{CH}_{2}\right)_{n}-\mathrm{OSO}_{3} \mathrm{Na}\right.$ : sodium octyl sulfate (SOS, Fluka), sodium decyl sulfate (SDeS, Sigma-Aldrich), sodium dodecyl sulfate (SDS, Sigma-Aldrich), sodium tetradecyl sulfate (STS, Fluka), and sodium hexadecyl sulfate (SHeS, Fluka)) were also studied.

Quinine sulfate from Fluka in 0.5 M sulfuric acid was used as standard for quantum yield measurements. ${ }^{16}$

\section{Apparatus and Methods}

Absorption spectra were recorded on a Shimadzu 2501 PC UV-visible spectrophotometer. For steady-state luminescence spectral measurements, a Shimadzu RF-5301 PC instrument was used in a right-angle configuration. The excitation wavelength was $381 \mathrm{~nm}$, and excitation and emission slits were 3 and 1.5 $\mathrm{nm}$, respectively. In general, absorption and emission spectra were measured at $25.0 \pm 0.1^{\circ} \mathrm{C}$, except for STSu, STS, SHeS, and $\mathrm{SHeSu}$, which were measured at $40.0 \pm 0.1{ }^{\circ} \mathrm{C}$ to be above the Krafft temperature. ${ }^{17}$ Time-resolved fluorescence measurements were carried out using the single photon counting technique with picosecond time resolution as previously described. ${ }^{18}$ Excitation of samples was carried out with the frequency-tripled output of an actively mode-locked picosecond Ti-sapphire laser (Spectra Physics Tsunami), pumped by a solid-state laser (Spectra Physics Millennia Xs). The repetition rate was set to $4 \mathrm{MHz}$ by passage through an optical-acoustic modulator (Pulse Selector 3980 Spectra Physics). Light pulses were monitored with a fast photodiode, filtered with a constant fraction discriminator (Canberra 2126), and used as stop signals in a time-to-amplitude converter (Canberra 2145 TAC). Excitation was vertically polarized, emission was collected with a $90^{\circ}$ geometry, passed through a polarizer at approximately $54.7^{\circ}$ (Spindler \& Hoyer Glan laser prism polarizer) and a monochromator (Jobin-Yvon H20 Vis), and detected with a microchannel plate photomultiplier tube (MCP-PT Hamamatsu $\mathrm{R} 3809 \mathrm{u}-50)$. Inverted start-stop configuration was used in the acquisition. The experimental instrumental response function for all excitation wavelengths was in the range 38-42 ps. Alternate collection of pulse profile and sample decays was performed $\left(10^{3}\right.$ counts at the maximum per cycle) until about 5 $\times 10^{3}$ (typical) to $3 \times 10^{4}$ total detected counts had been accumulated at the maximum of the fluorescence signal. The fluorescence decays were deconvoluted on a PC, using George Striker's Sand program $^{19}$ (LINUX version), which allows individual and global analysis of the decays with individual shift optimizations.

NMR spectra were recorded at $20^{\circ} \mathrm{C}$ on a Varian INOVA 400 spectrometer operating at $399.92 \mathrm{MHz}\left({ }^{1} \mathrm{H}\right) .{ }^{1} \mathrm{H}$ NMR spectra were registered of solutions of polymer (concentrations between $2.14 \times 10^{-3} \mathrm{M}$ and $3.97 \times 10^{-3} \mathrm{M}$ ) in DMSO- $\mathrm{D}_{2} \mathrm{O}$ $(4 \% \mathrm{v} / \mathrm{v})$ with sodium butyl sulfonate (SBSu, $0.531 \mathrm{M})$ and sodium decyl sulfonate ( $\mathrm{SDeSu}, 0.091 \mathrm{M}$ ) additions in $\mathrm{D}_{2} \mathrm{O}$. Solution electrical resistances were measured using a WayneKerr model 4265 Automatic LCR meter at $1 \mathrm{kHz}$. A Shedlovsky-type conductance cell was used. ${ }^{20}$ The cell constant (approximately $0.8465 \mathrm{~cm}^{-1}$ ) was determined to $\pm 0.02 \%$ from measurements with $\mathrm{KCl}$ (reagent grade, recrystallized and dried using the procedure and data from Barthel et al.). ${ }^{21}$ Measurements were made at $25.0 \pm 0.1{ }^{\circ} \mathrm{C}$ with cells in a Grant thermostat bath, except for the tetradecyl and hexadecyl surfactants, for which studies were made at $40.0 \pm 0.1{ }^{\circ} \mathrm{C}$.

\section{Results and Discussion}

We present initially the spectroscopic (absorption and emission) and electrical conductivity properties of HTMA-PFP in a DMSO-water solution $(4 \% \mathrm{v} / \mathrm{v})$. The study of the interaction between HTMA-PFP and sodium $n$-alkyl sufates and sulfonates using these techniques is reported in a separate section.

1. Polymer in a DMSO-Aqueous Solution (4\% DMSO). Absorption spectra of HTMA-PFP $\left(5.63 \times 10^{-6} \mathrm{M}\right.$ in terms of repeat units) in DMSO-water solutions (4\% v/v) show a broad peak with maximum at $378 \mathrm{~nm}$, while the emission spectra show a maximum at about $412 \mathrm{~nm}$, with shoulders at 434 and 471 $\mathrm{nm}$ (Figure 2). The fluorescence quantum yield $(\phi)$ in this solvent mixture is $0.52 \pm 0.03$, while the lifetime is $0.52 \pm$ $0.01 \mathrm{~ns}$. 

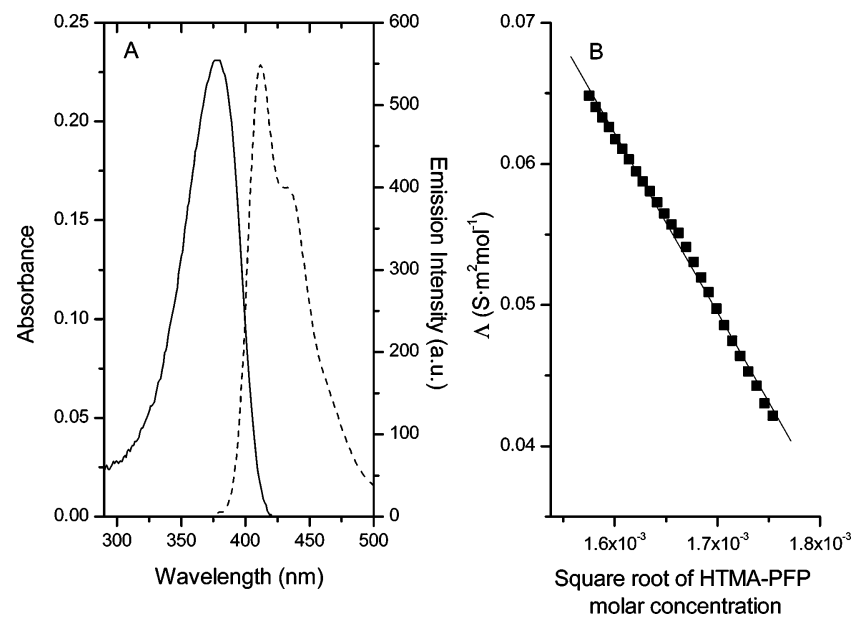

Figure 2. (A) Absorption and fluorescence spectra of HTMA-PFP solutions $\left(3.89 \times 10^{-3} \mathrm{~g} / \mathrm{L}, 5.63 \times 10^{-6} \mathrm{M}\right.$ in terms of repeat units $)$ in DMSO-water (4\% v/v); solid and dotted lines, respectively. (B) Molar conductivity of HTMA-PFP in DMSO-water mixtures (4\% v/v) versus square root of polymer molar concentration in terms of repeat units.

Studies at different concentrations show that the absorbance at $381 \mathrm{~nm}$ follows the Lambert-Beer law over the repeat unit concentration range $4 \times 10^{-7} \mathrm{M}$ to $3 \times 10^{-6} \mathrm{M}$. Both emission intensity and quantum yield increase linearly over the same range without significant changes in spectral shape, indicating that the polymer structure is not much affected by dilution for these polymer concentrations. A similar conclusion is obtained from molar conductivity data of HTMA-PFP at different concentrations in a DMSO-water mixture (4\% v/v). The molar conductivity, $\Lambda$, of HTMA-PFP is calculated using

$$
\Lambda=\left(\kappa-\kappa_{0}\right) /(c \times 1000)
$$

where $\kappa$ and $\kappa_{0}$ are the specific conductances of polyelectrolyte solution and solvent, respectively; and $c$ is the molar concentration in terms of repeat units $(\mathrm{mol} / \mathrm{L})$.

As has previously been observed for PBS-PFP, ${ }^{13 a, c}$ the molar conductivity of HTMA-PFP decreases linearly with the square root of polymer concentration (Kohlrausch law) between 1.58 $\times 10^{-3}$ and $1.72 \times 10^{-3} \mathrm{M}^{1 / 2}$ (Figure $2 \mathrm{~B}$ ). Using data shown in Figure 2B and the Kohlrausch equation, we obtain a molar limiting conductivity $\left(\Lambda_{0}\right)$ of $0.316 \pm 0.003 \mathrm{~S} \mathrm{~m}^{2} \mathrm{~mol}^{-1}$. This is approximately the same value as that found for poly $\{1,4-$ phenylene-[9,9-bis(4-phenoxy-butylsulfonate)]fluorene-2,7-diyl\}copolymer (PBS-PFP, $\bar{M}_{n}=\sim 6500 \mathrm{~g} \mathrm{~mol}^{-1} ; 0.36 \pm 0.01 \mathrm{~S}$ $\left.\mathrm{m}^{2} \mathrm{~mol}^{-1}\right){ }^{13 \mathrm{a}}$ This can be explained by the balance of two factors: the charge and the size of the HTMA-PFP sample which are around 3.7 times greater than those of the PBS-PFP studied; the increase of both factors contributes in the opposite way to the molar conductivity.

2. Polymer and $\boldsymbol{n}$-Alkyl Sulfonate Surfactant Interaction. Spectroscopic Results. The interaction between HTMA-PFP and sodium $n$-alkyl sulfonate surfactants was studied using absorption and fluorescence spectroscopy. The spectra of solutions were recorded at $25.0 \pm 0.1{ }^{\circ} \mathrm{C}$ with a polymer concentration around $5.5 \times 10^{-6} \mathrm{M}$ (in terms of repeat unit molar concentration) and various surfactant concentrations (from 0 up to $0.1 \mathrm{M}$ for surfactants with alkyl chains longer than dodecyl and up to $1 \mathrm{M}$ for the shorter chain length ones). Some scattering is observed in the spectra for higher surfactant concentrations for surfactants with alkyl chains longer than dodecyl.

The addition of $n$-alkyl sulfonate to HTMA-PFP aqueous solutions induces some changes in the absorption spectra as can

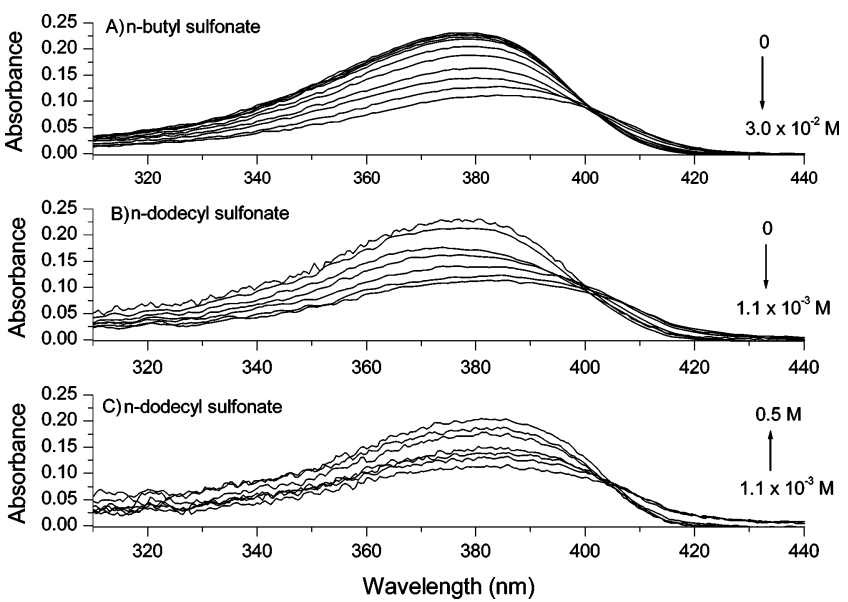

Figure 3. Absorption spectra of HTMA-PFP $\left(5.7 \times 10^{-6} \mathrm{M}\right.$ in repeat units) in 4\% DMSO-water, with (A) SBSu (concentrations 0 to $3.0 \times$ $10^{-2} \mathrm{M}$ ), (B) SDSu (concentrations in the pre-micellar region, 0 to 1.1 $\times 10^{-3} \mathrm{M}$ ) and $(\mathrm{C}) \mathrm{SDSu}$ (concentrations in the post-micellar region, $1.1 \times 10^{-3}$ to $5.0 \times 10^{-1} \mathrm{M}$ ). The arrows pointing up and down indicate increase and decrease of absorbance in the maximum $(\approx 378 \mathrm{~nm})$, respectively, while the surfactant concentration ranges are indicated at the right.

be seen for the butyl and dodecyl surfactants in Figure 3. While the initial additions of $n$-alkyl sulfonates do not significantly affect the absorbance (up to concentrations between $4 \times 10^{-7}$ $\mathrm{M}$ for SDSu and $5 \times 10^{-5} \mathrm{M}$ for SBSu), increasing surfactant concentration leads to a marked linear decrease of the characteristic polyfluorene absorption band at around $378 \mathrm{~nm}$, accompanied by an increase in absorbance at wavelengths greater than $400 \mathrm{~nm}$. For most of these systems, a well-defined isosbestic point is also observed around this wavelength (Figure 3 ), suggesting the presence of a single equilibrium. In all cases, a minimum is observed in the absorbance (corresponding to around $40 \%$ of the initial values), with the concentration at which this occurs depending upon the surfactant chain length (from $5 \times 10^{-5} \mathrm{M}$ for dodecyl to $4 \times 10^{-2} \mathrm{M}$ for butyl (Figure 4A). A similar broadening of the absorption spectra and reduction in absorbance has previously been reported with the structurally related poly(9,9-bis $\left(6^{\prime}-(N, N, N\right.$-trimethylammonium)hexyl)fluorenephenylene) copolymer and related oligomers upon addition of SDS, ${ }^{22}$ although no explanation was presented.

Increasing surfactant concentration does not affect absorbance until around the critical micelle concentration (cmc; Table 1; between $1 \times 10^{-3} \mathrm{M}$ for SDSu and $0.4 \mathrm{M}$ for SHSu). However, in general, absorbance increases again above the cmc and in some cases (e.g., SDeSu) reaches values even higher than in the absence of surfactants. This increase of absorbance is not observed for the butyl compounds; see Figure 4A.

Moreover, these changes are accompanied by shifts in absorption maxima. Similar wavelength shifts are seen in the fluorescence spectra, as can be seen in Figure 4B,D. As with the absorption spectra, no shift is seen in emission maxima upon initial surfactant additions. However, red shifts in both absorption and emission maxima are observed in the $n$-alkyl sulfonate concentration range for which the absorbances and emission intensities decrease. These red shifts vary from $9 \mathrm{~nm}$ (377$385 \mathrm{~nm}$ ) for SDSu to a $3 \mathrm{~nm}$ increment $(377-380 \mathrm{~nm})$ for octyl sulfonate in absorption spectra and with fluorescence from around $10 \mathrm{~nm}$ (from 412 to $422 \mathrm{~nm}$ ) to $6 \mathrm{~nm}$ (from 412 to 418 $\mathrm{nm}$ ) for the longer alkyl chain surfactants (dodecyl, tetradecyl, and hexadecyl). No shifts in spectral maxima are observed at surfactant concentrations above the zone of the minimum plateau of the absorbance or emission intensity; see Figure 4. 

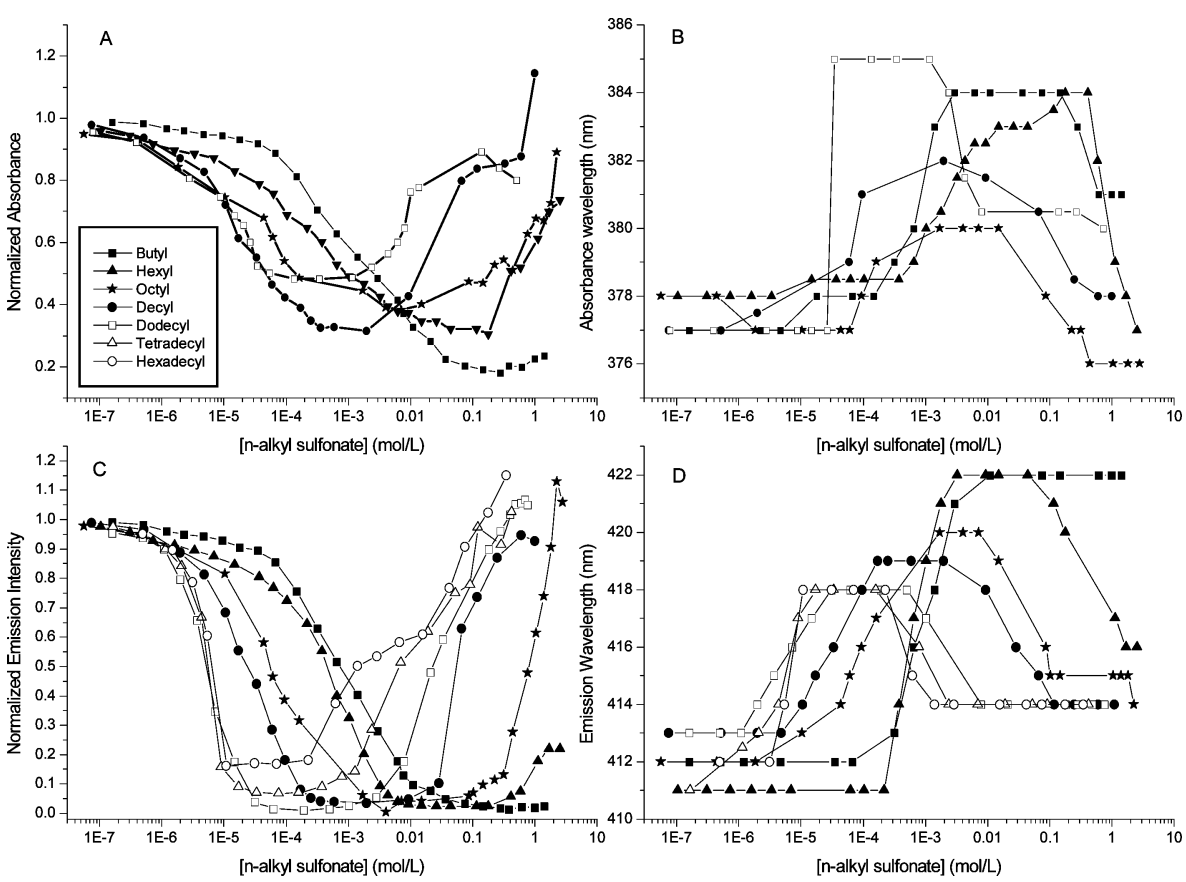

Figure 4. (A) Normalized absorbance, (B) absorbance maximum wavelength, (C) normalized emission intensity and (D) emission maximum wavelength versus $n$-alkyl sulfonate molar concentration (moles per liter) on a logarithmic scale.

TABLE 1: Comparison between Literature Sodium $\boldsymbol{n}$-Alkyl Sulfonate c.m.c Values in Aqueous Solution, the Surfactant Concentrations at Which HTMA-PFP Emission Intensity Is Recovered or Emission Wavelength Decreases Once It Has Reached a Maximum Value and Sodium $n$-Alkyl Sulfonates CMC Values in 4\% DMSO-Water Obtained from Conductivity Data

\begin{tabular}{|c|c|c|c|c|c|c|c|}
\hline \multirow[b]{2}{*}{ parameter } & \multicolumn{7}{|c|}{ sodium $n$-alkyl sulfonates } \\
\hline & butyl & hexyl & octyl & decyl & dodecyl & tetradecyl & hexadecyl \\
\hline literature $\mathrm{cmc}$ value $(\mathrm{mol} / \mathrm{L})^{24}$ & & $5.0 \times 10^{-1}$ & $1.5 \times 10^{-1}$ & $\begin{array}{c}2.1 \times 10^{-2} \\
\left( \pm 9.1 \times 10^{-3}\right)\end{array}$ & $\begin{array}{c}9.8 \times 10^{-3} \\
\left( \pm 2.0 \times 10^{-4}\right)\end{array}$ & $\begin{array}{c}1.9 \times 10^{-3} \\
\left( \pm 2.0 \times 10^{-4}\right)\end{array}$ & $\begin{array}{r}6.1 \times 10^{-4} \\
\left( \pm 9.0 \times 10^{-5}\right)\end{array}$ \\
\hline emission intensity & & $4.8 \times 10^{-1}$ & $9.7 \times 10^{-1}$ & $3.2 \times 10^{-2}$ & $7.9 \times 10^{-3}$ & $1.1 \times 10^{-3}$ & $2.3 \times 10^{-4}$ \\
\hline emission wavelength & & $\begin{array}{r}3.7 \times 10^{-1} \\
\left(+5.8 \times 10^{-2}\right)\end{array}$ & $\begin{array}{r}1.2 \times 10^{-1} \\
\left(+11 \times 10^{-2}\right.\end{array}$ & $\begin{array}{r}4.0 \times 10^{-3} \\
\left(+14 \times 10^{-4}\right)\end{array}$ & $\begin{array}{r}4.3 \times 10^{-3} \\
\left(+21 \times 10^{-4}\right)\end{array}$ & $\begin{array}{r}3.0 \times 10^{-4} \\
\left(+6.2 \times 10^{-5}\right)\end{array}$ & $\begin{array}{r}2.0 \times 10^{-4} \\
+98 \times 10^{-6}\end{array}$ \\
\hline specific conductivity & & & & $\begin{array}{r}3.3 \times 10^{-2} \\
\left( \pm 3.3 \times 10^{-4}\right)\end{array}$ & $\begin{array}{r}1.2 \times 10^{-2} \\
\left( \pm 2.0 \times 10^{-5}\right)\end{array}$ & $\begin{array}{r}2.2 \times 10^{-3} \\
\left( \pm 4.0 \times 10^{-5}\right)\end{array}$ & $\begin{array}{r}7.6 \times 10^{-4} \\
\left( \pm 6.5 \times 10^{-5}\right)\end{array}$ \\
\hline
\end{tabular}

For surfactant concentrations above the cmc, some differences in the maximum shifts are observed between absorption and emission. In absorption, the maximum of spectra are continuously blue-shifted for surfactant concentration above the $\mathrm{cmc}$ to values close to the initial ones (Figure 4B). However, a marked blue shift is seen with the fluorescence maximum up to around $414 \mathrm{~nm}$ for surfactant concentrations close to the $\mathrm{cmc}$ (Table 1), while, in general, further increases in surfactant concentration do not produce any further change in the emission maxima (Figure 4D). As with the absorbance, the exception to this behavior is $n$-butyl sulfonate, which, in terms of chain length, can be considered to be at the lower limit of surfactant behavior. Normally, with amphiphiles, at least eight carbon atoms are considered to be necessary for surfactant behavior in aqueous solutions. ${ }^{23}$

In addition to the shifts in the fluorescence maxima, addition of $n$-alkyl sulfonates also leads to changes of the spectral band shape. The shoulders at 434 and $471 \mathrm{~nm}$ become better defined, corresponding to a more resolved vibrational structure (Figure $5 \mathrm{~A}$ ), while the ratio of the intensity at the maximum to that at the shoulder increases, in particular, above the cmc. This may reflect a decrease in the number of conformations present in the emitting state. In contrast, no significant changes are observed in the shapes of the normalized absorption spectra.

Upon initial surfactant additions, the emission quantum yield is nearly constant (surfactant concentrations up to $4 \times 10^{-7} \mathrm{M}$ for SHeSu and $5 \times 10^{-5} \mathrm{M}$ for $\mathrm{SBSu}$, Figure 4C). However, increasing the concentration of the surfactant (up to $1 \times 10^{-5}$ $\mathrm{M}$ for the hexadecyl and $1 \times 10^{-2} \mathrm{M}$ for the butyl sulfonates) leads to almost a complete quenching of the polymer emission (quantum yield, $\phi$, below 0.1 ). For surfactants with $n$-alkyl chain length longer than hexyl, the HTMA-PFP emission is recovered upon further additions of surfactant and, in some cases, even enhanced for concentrations above the cmc compared with solutions in the absence of surfactant. In the case of butyl, no increase of emission intensity is observed.

A good agreement is found between the surfactant concentrations at which the polymer emission intensity increases and their cmc values (Table 1), indicating that HTMA-PFP could be used as a sensitive fluorescent probe to detect micelle formation in $n$-alkyl sulfonates and probably other anionic surfactants. The variation in emission maximum wavelength can also provide an estimation of the cmc by using the crossing point of the two lines corresponding to the maximum red shift of emission and the range for which emission wavelength decreases as functions of surfactant concentration. The cmc values obtained from these crossing points are, in general, slightly lower than the literature ones (Table 1).

To check whether the functional group of the surfactant has any significant effect on the polymer-surfactant interaction, similar spectroscopic experiments were carried out using sodium octyl sulfate, decyl sulfate, and dodecyl sulfate. No significant effects of headgroups were observed, and surfactants with sulfate 

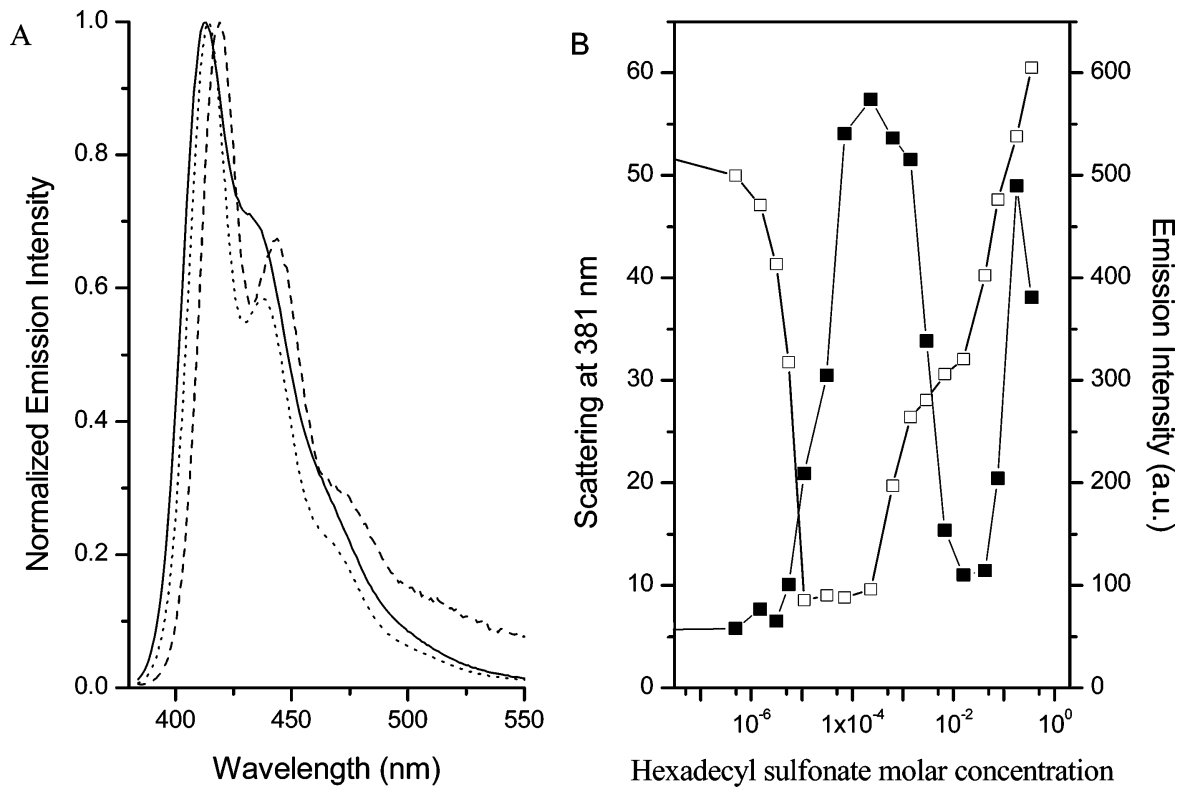

Figure 5. (A) Normalized emission spectra of HTMA-PFP $\left(7.39 \times 10^{-6} \mathrm{M}\right.$, in terms of repeat units) in aqueous solution with $4 \%$ DMSO for several sodium decyl sulfonate concentrations: $0,1.39 \times 10^{-3}$ and $1.1 \times 10^{-1} \mathrm{M}$; solid, dashed, and dotted lines, respectively. (B) Rayleigh scattering at $381 \mathrm{~nm}$ (full squares) and emission intensity (empty squares) of HTMA-PFP $\left(6.6 \times 10^{-6} \mathrm{M}\right.$, in terms of repeat units) in $4 \%$ (v/v) DMSO-water versus hexadecyl sulfonate molar concentration (logarithmic scale).

TABLE 2: HTMA-PFP $n$-Alkyl Sulfonate Stern-Volmer Constants Determined by Eq 2

\begin{tabular}{|c|c|c|c|c|c|c|c|}
\hline$n$-alkyl sulfonate & butyl & hexyl & octyl & decyl & dodecyl & tetradecyl & hexadecyl \\
\hline$K_{\mathrm{SV}}\left(\mathrm{L} \cdot \mathrm{mol}^{-1}\right)$ & $7.81 \times 10^{2}$ & $1.36 \times 10^{3}$ & $1.13 \times 10^{4}$ & $6.92 \times 10^{4}$ & $3.48 \times 10^{5}$ & $7.69 \times 10^{5}$ & $6.40 \times 10^{5}$ \\
\hline
\end{tabular}

and sulfonate groups have both been used in the subsequent experiments to obtain the best experimental conditions.

Fluorescence quenching and a decrease in absorbance of polyfluorenes has previously been reported for the anionic polymer (PBS-PFP) upon addition of oppositely charged tetralkyl ammonium surfactants below the cmc. ${ }^{13 b}$ As we have proposed for PBS-PFP with tetralkyl ammonium surfactants, we believe that the quenching observed in HTMA-PFP- $n$-alkyl sulfonate systems is due to polymer aggregation favored by the charge neutralization upon interaction with surfactants.

The formation of polymer aggregates between polymer chains upon neutralization by the interaction with surfactant is compatible with the observed increase in Rayleigh scattering at the fluorescence excitation wavelength $(381 \mathrm{~nm})$, as shown in Figure 5B for the hexadecyl surfactant. This scattering increase is proportional to the emission intensity decrease, and both curves have a common inflection point, suggesting a common origin, the formation of polymer aggregates.

Quenching of the polymer fluorescence by sodium $n$-alkyl sulfonates was found to follow Stern-Volmer kinetics:

$$
\frac{F_{0}}{F}=1+K_{\mathrm{SV}} \cdot[Q]
$$

where $F_{0}$ and $F$ are HTMA-PFP emission intensities in the absence and presence of quencher, respectively; $K_{\mathrm{SV}}$ is the Stern-Volmer constant, and $[Q]$ is the molar concentration of the quencher (surfactant concentration). The Stern-Volmer constants are shown in Table 2.

To gain some insight into the nature of the quenching process, values of $K_{\mathrm{SV}}$ for butyl and decyl sulfonates have been determined at various temperatures (from 25 to $45^{\circ} \mathrm{C}$ ). No significant changes are observed in either absorption or emission spectra of HTMA-PFP in aqueous solutions upon changing temperature. However, when $n$-alkyl sulfonates are added, notable differences are seen. With both SBSu and SDeSu, upon increasing temperature, increases in polymer emission intensity and, consequently, decreases in the Stern-Volmer constants were observed. These followed the Arrhenius law and, for example, went from $1.1 \times 10^{5}$ at $25^{\circ} \mathrm{C}$ to $4.1 \times 10^{4} \mathrm{~L} \mathrm{~mol}^{-1}$ at $45^{\circ} \mathrm{C}$ for SDeSu. The calculated activation energies for these regions are -39.6 and $-48.7 \mathrm{~kJ} \mathrm{~mol}^{-1}$ for SDeSu and SBSu, respectively. If fluorescence quenching involved predominantly a dynamic process, this would be expected to increase with temperature. The decrease in the Stern-Volmer constant with increasing temperature therefore indicates that the dominant contribution comes from static quenching because of the formation of some kind of mixed polymer-surfactant aggregates.

To obtain more information about the nature of the quenching process and to further characterize the species present, timeresolved fluorescence experiments were carried out with HTMAPFP in DMSO-water $4 \% \mathrm{v} / \mathrm{v}$ alone and in the presence of various concentrations of SDeSu. The emission was recorded at 416 and $450 \mathrm{~nm}$ (main emission band and shoulder, respectively) with excitation at $380 \mathrm{~nm}$. No major changes were found between the data obtained at these two wavelengths. Good fittings could be obtained with triexponential decays at low surfactant concentrations and biexponential ones at higher concentrations (details are given in Supporting Information).

Average decay times for the triexponentional fittings are around 30, 100, and $460 \mathrm{ps,} \mathrm{while} \mathrm{for} \mathrm{biexponential} \mathrm{fittings,}$ the shortest lifetime component is missing. The longest decay time is assigned to the pure polymer lifetime, since it is the dominant component at sufficiently high surfactant concentrations and its value is of a similar order of magnitude to that of other polyfluorene lifetimes: $360 \mathrm{ps}$ for PBS-PFP in water ${ }^{13 a}$ and $340 \mathrm{ps}$ for poly(9,9-dioctylfluorene) in $\mathrm{MCH}$ at $298 \mathrm{~K} \cdot{ }^{25}$ From the fluorescence quantum yield (0.53) and lifetime (508 ps) of HTMA-PFP in 4\% v/v DMSO-water in the absence 


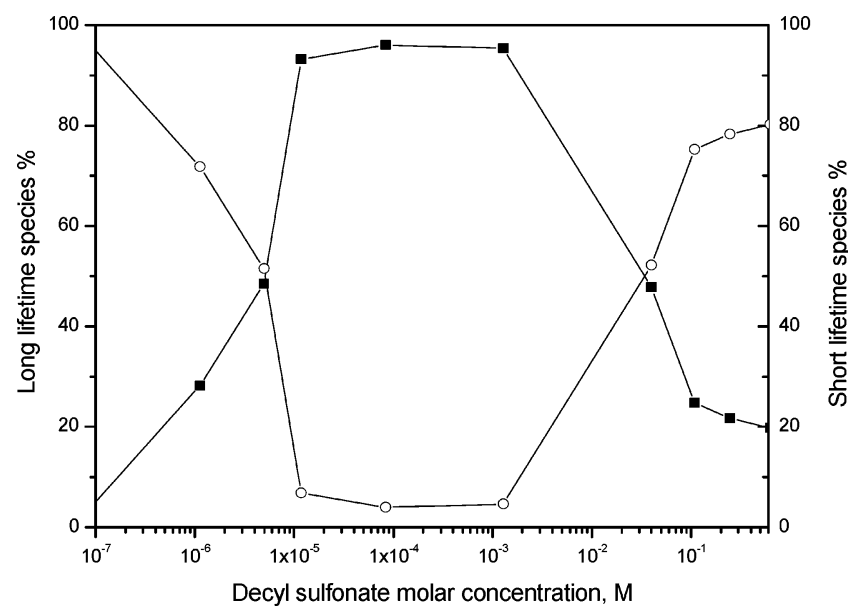

Figure 6. HTMA-PFP $\left(4.12 \times 10^{-6} \mathrm{M}\right.$ repeat units, $4 \% \mathrm{v} / \mathrm{v}$ DMSOwater): amplitudes (percentage) of long and short fluorescence lifetime species at $416 \mathrm{~nm}$ (empty circles and full squares respectively) versus sodium decyl sulfonate concentration (logarithmic scale). In the region where triexponentional fittings are necessary, the short lifetime species percentage is the sum of the values from amplitudes of the two fast components.

of surfactant, the calculated nonradiative, $k_{\mathrm{nr}}$ and radiative rate constants, $k_{\mathrm{f}}$, are $9.25 \times 10^{8} \mathrm{~s}^{-1}$ and $1.04 \times 10^{9} \mathrm{~s}^{-1}$, respectively.

The ratio $\tau_{0} / \tau$ (lifetimes in the absence/in the presence of surfactant) for the longest lifetime components was plotted versus both $\mathrm{SDeSu}$ and aggregate concentrations. Stern-Volmer plots in both cases showed poor correlations and no significant variations with concentration, indicating, in agreement with the temperature effect on steady state measurements, that we are seeing mainly static quenching and supporting the idea that is due to surfactant induced polymer aggregate formation.

From the decay times $\tau_{i}$ and respective pre-exponentional factors $a_{i}$ (see Supporting Information), the relative contributions of the three decay components to the total time-integrated fluorescence $\left(I_{i}=\int_{0}^{\infty} a_{i} \mathrm{e}^{-t / \tau_{i}} \mathrm{~d} t=a_{i} \times \tau_{i}\right)$ can be calculated. The percentage of the fluorescence contribution of the two short decay times $\left(I_{2}+I_{3}\right)$ and that of the longest component $I_{1}$ are plotted versus SDeSu molar concentration in Figure 6. The trend of the normal (long-lived) emission $I_{1}$ versus [SDeSu] is identical to that of the steady-state emission intensity (Figure 4C and Figure 6). At surfactant concentrations well below the cmc, $I_{1}$ sharply decreases with the addition of surfactant, while it then recovers its initial value at concentrations close to the cmc. We believe that it is significant that the changes in fluorescence intensity result essentially from the changes of the pre-exponential factor of the longest component and not from its decay time. This indicates that the long-lived emission from isolated polymer chains is initially replaced by species with shorter fluorescence lifetimes upon addition of surfactant. This is, in turn, replaced by species with long-lived fluorescence for surfactant concentrations above cmc. We believe that this suggests that both the short-lived emissions and the new long-lived emitting species are due to the presence of polymer-surfactant species. The two short-lived components are probably due to surfactant induced polymer aggregates formed upon neutralization, as discussed with the steady-state results.

From the fact that there are two components produced in different surfactant concentration regions, it can be deduced that there are probably two distinct types of polymer-surfactant aggregates, although, with the information available, it is not yet possible to attribute structures to them.
One observation supporting a single-step aggregation process in these systems for surfactant concentrations considerably below cmc is the observation of an isosbestic point in the absorption spectra (Figure 3). This indicates a pseudo-equilibrium, assumed to be due to the formation of surfactant induced polymer aggregates and can be expressed as:

$$
\mathrm{P}+\mathrm{P} \stackrel{K_{\mathrm{A}}}{\rightleftarrows} \mathrm{A}
$$

where $\mathrm{P}$ are assumed to be either polymer aggregates or single polymer chains that form higher order aggregates, A, as a consequence of polymer charge neutralization upon interaction with surfactants in the pre-micellar region, and $K_{\mathrm{A}}$ is the aggregation constant.

Aggregate concentrations, absorption spectra, and values of $K_{\mathrm{A}}$ were calculated using an iterative method proposed by Lopez Arbeloa $^{26}$ to study aggregation of dyes in solution. According to this method, slightly adapted for our systems, the aggregation constant can be expressed as: ${ }^{26}$

$$
K_{\mathrm{A}}=\frac{1-x}{2 \cdot c \cdot x^{2}}
$$

where $x$ is, in this case, the molar fraction of $\mathrm{P}$ and $c$ is the polymer molar concentration.

As has been proposed by Lopéz Arbeloa, ${ }^{26}$ the molar absorption coefficient at any wavelength $\left(\bar{\epsilon}_{\lambda}\right)$ can be expressed as:

$$
\bar{\epsilon}_{\lambda}=\overline{\epsilon_{\lambda}^{\mathrm{P}}} x+\overline{\epsilon_{\lambda}^{\mathrm{A}}}(1-x)
$$

where $\overline{\epsilon_{\lambda}^{P}}$ and $\overline{\epsilon_{\lambda}^{A}}$ are the average molar absorption coefficients of $\mathrm{P}$ and $\mathrm{A}$, respectively. It is assumed that single chains (P) (or possibly lower order aggregates) are the only species present in the absence of surfactant and that these have identical spectra. Under these conditions, the absorption spectrum will be that of P: $\bar{\epsilon}_{\lambda}=\overline{\epsilon_{\lambda}^{\mathrm{P}}}$.

From eq 5, the molar absorption coefficients of higher order aggregates, $\overline{\epsilon_{\lambda}^{\mathrm{A}}}$, can be determined if $x$ is known. The P molar fraction can be determined by an iterative method ${ }^{26}$ leading to a limiting $x$ value obtained when differences of 0.02 are observed between consecutive calculated $x$ values.

The parameter $R$ is defined as: ${ }^{26}$

$$
R=\frac{A_{\lambda A}}{A_{\lambda \mathrm{P}}}=\frac{\overline{\epsilon_{\lambda \mathrm{A}}^{\mathrm{P}}} x+\overline{\epsilon_{\lambda \mathrm{A}}^{\mathrm{A}}}(1-x)}{\overline{\epsilon_{\lambda \mathrm{P}}^{\mathrm{P}}} x+\overline{\epsilon_{\lambda \mathrm{P}}^{\mathrm{A}}}(1-x)}
$$

where $A_{\lambda \mathrm{P}}$ and $A_{\lambda \mathrm{A}}$ are the experimental absorbances at $\mathrm{P}$ and A wavelength maxima, respectively. The maximum absorbance wavelength of $\mathrm{P}$ is assumed to be that of the HTMA-PFP absorption spectrum in the absence of surfactant (around 381 $\mathrm{nm})$. The absorption maximum for A has been calculated by subtracting the pure polymer absorption spectrum from an HTMA-PFP absorption spectrum at the highest surfactant concentration for which the isosbestic point (at about $400 \mathrm{~nm}$ ) is still well-defined.

Parameter $R$ becomes $R_{0}$ when $x \cong 1^{26}$ (i.e., in the absence of surfactant):

$$
R_{0}=\frac{\overline{\epsilon_{\lambda \mathrm{A}}^{\mathrm{P}}}}{\overline{\epsilon_{\lambda \mathrm{P}}^{\mathrm{P}}}}
$$

In this situation, no higher order aggregates are considered to be present. 


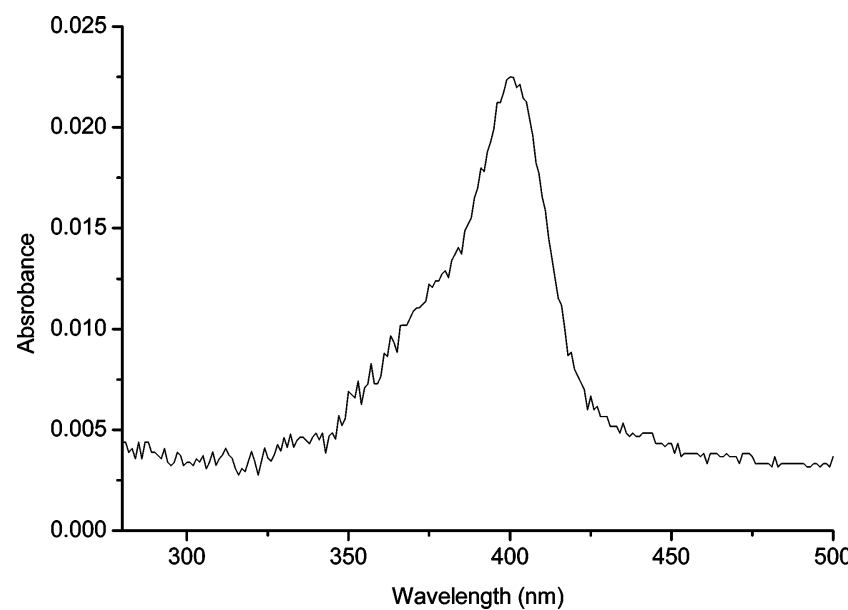

Figure 7. Aggregate absorption spectrum obtained by iterative process for HTMA-PFP with sodium tetradecyl sulfonate $\left(7.35 \times 10^{-5} \mathrm{M}\right)$.

To obtain a first approximate value of $x^{(1)}$, it is assumed that $\overline{\epsilon_{\lambda \mathrm{P}}^{\mathrm{A}}}<<\overline{\epsilon_{\lambda \mathrm{P}}^{\mathrm{P}}}$ and $\overline{\epsilon_{\lambda \mathrm{A}}^{\mathrm{A}}} \cong \overline{\epsilon_{\lambda \mathrm{A}}^{\mathrm{P}}}$, leading to an approximate molar fraction that allows the calculation of $K_{\mathrm{A}}$, molar concentration of $\mathrm{A}, \overline{\epsilon_{\lambda \mathrm{A}}^{\mathrm{A}}}$ and $\overline{\epsilon_{\lambda \mathrm{P}}^{\mathrm{A}}}$ from eqs 4 and 5 .

$$
x(1)=\frac{R_{0}}{R}
$$

These calculated average molar absorption coefficient values are then used to estimate a second value of $x^{(2)}$ with eq 6 and a second value of association constant and aggregate molar absorption coefficients (eqs 4 and 5). The convergence of the $x$ values is normally reached with less than 10 iterations for the surfactant concentration range in which a strong quenching is observed. With these $x$ values, the aggregate absorption spectra are calculated from eq 5. Similar spectra are obtained with all of the surfactants studied and consist of a narrow peak with a maximum at around $402 \mathrm{~nm}$ and a shoulder around $376 \mathrm{~nm}$, as is shown in Figure 7 for STSu. Most of the $K_{\mathrm{A}}$ values obtained, within these concentration ranges, are between $4 \times 10^{5}$ and 1 $\times 10^{6} \mathrm{~mol}^{-1} \mathrm{~L}$, although they apparently do not follow any trend with the $n$-alkyl chain length.

One of the surprising results obtained in this study is that, following almost complete quenching of polymer emission as a consequence of surfactant addition, further additions lead to the recovery of absorbance and emission intensity in the region of the surfactant cmc and in some cases give values even greater than those observed for the pure polymer solutions (Figure 4C). If the quenching process is attributed to surfactant induced polymer aggregation, it seems reasonable that the increase in the absorbance and emission intensity is due to disruption of these polymer aggregates as a consequence of surfactant micelle formation, as has been proposed for other fluorene based conjugated polyelectrolytes with surfactants. ${ }^{13 a, c, e, f}$ As has previously been discussed, experimental evidence of polymer aggregate disruption upon reaching the surfactant $\mathrm{cmc}$ comes from the Rayleigh scattering at $381 \mathrm{~nm}$ (Figure 5B). The increase of HTMA-PFP emission intensity parallels the decrease of scattering above the $\mathrm{SHeSu} \mathrm{cmc}$, which is compatible with disruption of polymer aggregates. For surfactant concentrations above $3.7 \times 10^{-2} \mathrm{M}$, the increase of scattering is probably due to phase separation, as is observed visually.

Further information on these aggregation processes comes from ${ }^{1} \mathrm{H}$ NMR experiments. ${ }^{1} \mathrm{H}$ NMR spectra were run of HTMA-PFP in DMSO (a good solvent for this polymer), in DMSO-water $(4 \% \mathrm{v} / \mathrm{v})$ and in the same solvent mixture upon
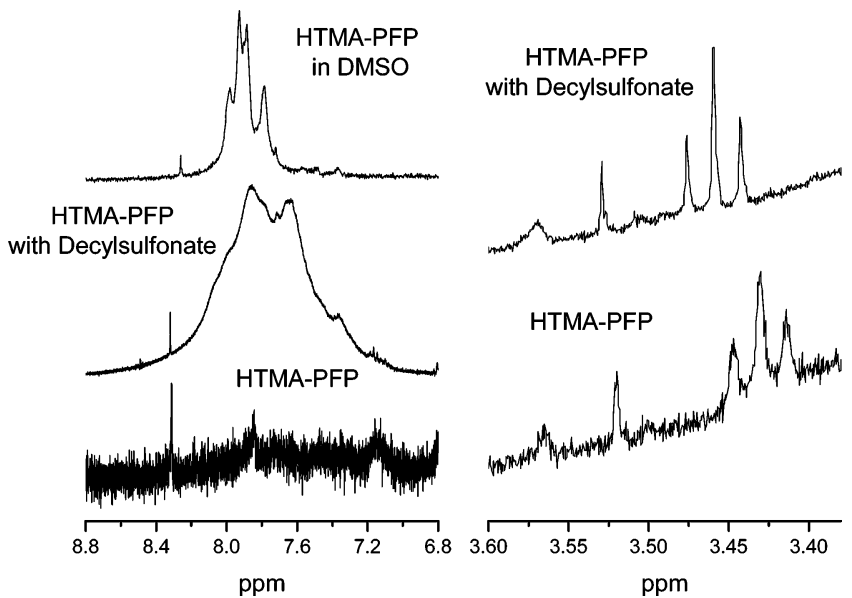

Figure 8. HTMA-PFP (DMSO/water $1 \%(\mathrm{v} / \mathrm{v})$ ) with and without sodium decyl sulfonate $0.09 \mathrm{M}{ }^{1} \mathrm{H}$ NMR spectra and HTMA-PFP in DMSO upper left spectra.

addition of decyl sulfonate $(0.1 \mathrm{M}$, above the $\mathrm{cmc})$ and butyl sulfonate $(0.44 \mathrm{M})$. The most interesting changes are observed in the aromatic region. Sharp characteristic aromatic polyfluorene signals are observed at around $7.8 \mathrm{ppm}$ in DMSO. These are very weak in mixtures of DMSO-water (1\% v/v; Figure 8) or with SBSu (not shown) and become broadened in the presence of SDeSu. In contrast, in the aliphatic region, the effect of adding SDeSu is not so marked, with only a slight sharpening of the signals observed, as can be seen with the triplet signal shown in Figure 8, attributed to one of the methylene groups coupled to an adjacent $-\mathrm{CH}_{2}$ in the alkyl side chain. If we assume that the signals in the aromatic region in DMSO- $d^{6}$ solution correspond to those of freely rotating fluorenephenylene backbones, the broadening observed in this region in the presence of SDeSu suggests more restricted motion, associated with formation of polymer-surfactant aggregates, possibly having a micellar structure. This becomes even more pronounced in the absence of surfactant (or with the "poor" surfactant SBSu, where no micelles are present under these experimental conditions), possibly because of backbonebackbone interactions resulting from closer interchain contact. In contrast, the well-resolved alkyl signals both in DMSO/water and in the presence of SDeSu indicate relatively free motion of the side chains. The linewidths appear slightly narrower in the presence of the surfactant, but in the absence of detailed NMR relaxation time measurements (which are outside the scope of this study), it is risky to speculate on the origin of this.

Conductivity. Specific conductance of sodium octyl, decyl, dodecyl, tetradecyl, and hexadecyl sulfates and sulfonates, as a function of surfactant concentration, have been measured in DMSO-water mixtures $(4 \% \mathrm{v} / \mathrm{v})$ to test the effect of the small fraction of DMSO on the cmc values. The specific conductance, $\kappa$, increases linearly with surfactant concentration, showing two different slopes, corresponding to initially the presence of unimers and, when the slope of $\kappa=f(c)$ decreases, micelles. The parameters of the linear fittings in the pre-micellar and postmicellar region of the pure surfactant in DMSO-water and the cmc values are given in Supporting Information for comparison with the same parameters for surfactant solutions in the presence of polymer.

The critical micelle concentration of these surfactants in DMSO-water $(4 \% \mathrm{v} / \mathrm{v})$ and in aqueous solution have been given in Table 1, and indicate that, within experimental error, the addition of $4 \%$ of DMSO has little significant effect on the cmc. 

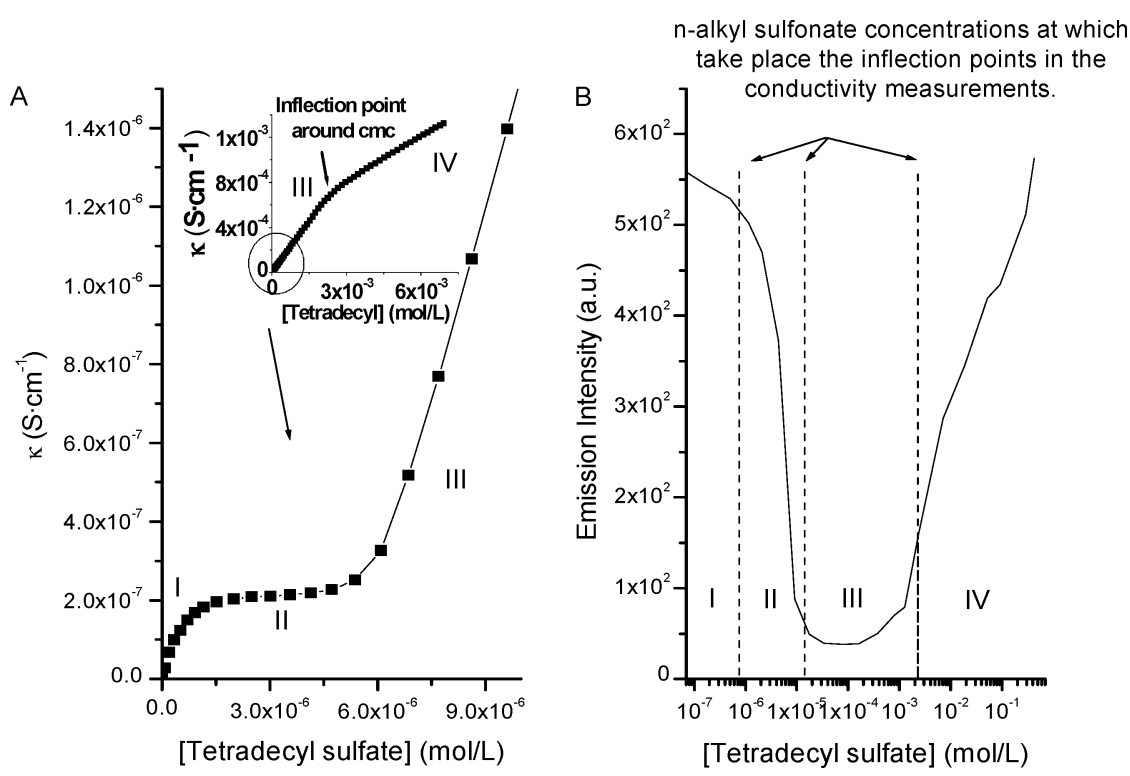

Figure 9. (A) Specific conductivity, $\kappa$, versus sodium tetradecyl sulfate concentration in a HTMA-PFP solution $6.72 \times 10^{-6} \mathrm{M}$. (DMSO-water $4 \% \mathrm{v} / \mathrm{v})$. Inset: the same data for the whole surfactant concentrations range $(\mathrm{B})$ HTMA-PFP $\left(6.65 \times 10^{-6} \mathrm{M}\right)$ solution with sodium tetradecyl sulfate additions emission intensity in DMSO-water $4 \%(\mathrm{v} / \mathrm{v})$ (solid line). Dashed lines: Surfactant concentrations at which changes in slopes of conductivity plots (inflection points) are observed.

A typical plot of specific conductance, $\kappa$, of solutions of polymer (with concentration about $5.5 \times 10^{-6} \mathrm{M}$ in terms of repeat unit) as a function of the surfactant concentration is shown in Figure 9A. Two different types of behavior can be identified in this figure. At surfactant concentrations much greater than the polymer concentration (inset of Figure 9A), the specific conductance increases linearly with surfactant concentration and shows two different slopes (concentration ranges III and IV, in Supporting Information). Surfactant $\mathrm{cmc}$ values calculated as the crossing point of these two lines are shown in Supporting Information and are very similar to those obtained in the absence of polymer (Table 1). The largest deviation is for $\mathrm{SHeSu}$. It is worth pointing out that the slopes of the linear fittings in these regions ( $m$, Supporting Information) are very close to those found for the surfactant in the absence of the polymer, which suggests that within this surfactant concentration range $\left(\geq 10^{-5}\right.$ or $10^{-4} \mathrm{M}$ ) the surfactant counterion dissociation (which is one of the main contributions to the conductivity) is not affected by the presence of polymer. From this, we may conclude that, at high surfactant concentrations, the solution ionic conductivity is mainly controlled by the surfactant. This is very reasonable since the surfactant concentrations are several orders of magnitude greater than that of the polymer in this region.

For $\mathrm{SHeSu}$, an additional inflection point is observed above the cmc both in conductivity and emission intensity measurements (Figure $4 \mathrm{C}$ and Supporting Information), and since it is not observed with the pure sodium hexadecyl surfactant solutions, this can be attributed to formation of some species formed through the interaction between polymer and surfactant. The low cmc of SHeSu in comparison with the other surfactants may be responsible for observing micelle-polymer interaction in the conductivity data, even above $\mathrm{cmc}$, since, for this surfactant, the concentration of micelles ([SHeSu]/aggregation number) at the cmc is practically equal to the molar concentration of repeat units, while for the other surfactants, the micelle concentration is considerably greater than the number of polymer charged groups. From the $\mathrm{cmc}$ of $n$-alkylsulfonate in the presence of polymer (values shown in Supporting Information), assuming aggregation numbers of 65, 90, 110, and 120 for $\mathrm{SDeSu}, \mathrm{SDSu}, \mathrm{STSu}$, and $\mathrm{SHeSu}$, respectively (as for the corresponding sulfate derivatives), ${ }^{27}$ the concentration of micelles for each surfactant will be $5.1 \times 10^{-4}, 1.2 \times 10^{-4}, 2.1$ $\times 10^{-5}$, and $7.5 \times 10^{-6}$ moles of micelles/L, respectively. For the hexadecyl surfactant, a new inflection point appears for a surfactant concentration $2.7 \times 10^{-3} \mathrm{M}$, which represents a micelle concentration $2.2 \times 10^{-5}$ mole of micelles/L, while the repeat unit and charge group concentrations of the polymer are $6.9 \times 10^{-6} \mathrm{M}$ and $1.4 \times 10^{-5} \mathrm{M}$, respectively. This second inflection point thus appears when the concentration of micelles is around 1.6 times that of the charged groups. This would appear to be compatible with a pearl necklace model of polymer-surfactant aggregation in which the cationic sites are the initial binding sites around which micelle-like aggregates are clustered. ${ }^{28}$ However, on structural grounds, we have previously argued against such a model for these fluorenephenylene based copolymers, ${ }^{13 \mathrm{c}}$ since the backbone rigidity does not allow easy stabilization of spherical micelles along its chain. Nevertheless, the fact that the same effect is not observed with the lower alkyl chain length surfactants, where the micelle concentration above $\mathrm{cmc}$ is markedly greater than the concentration of polymer charged groups under our experimental conditions, indicates that some kind of surfactant aggregation is occurring along the polymer chain. We believe that one structurally realistic possibility is the formation of hemimicelles along the chain, as has previously been observed with ionic surfactants adsorbed onto hydrophobic surfaces. ${ }^{29}$

Significant differences were found between the specific conductivity of surfactant and surfactant-polymer solutions in DMSO-water mixtures $(4 \% \mathrm{v} / \mathrm{v})$ for small additions of surfactant in all of the systems studied, when the surfactant and polymer concentrations (in terms of repeat unit) are comparable (see Figure 9A). In the pure surfactant system, specific conductivity grows linearly over the whole concentration range up to the cmc with a constant slope of the plot of $\kappa$ versus surfactant concentration. In contrast, in the presence of the polymer, the specific conductivity of HTMA-PFP-surfactant solutions shows three different linear surfactant concentration regions below the cmc (I, II, and III, see Table 2 in Supporting Information), with different slopes, as can be seen in the same table. Initially, the addition of surfactants (normally below 
$10^{-7} \mathrm{M}$ ) leads to an increase in the electrical conductance of the surfactant/polymer mixture until a first inflection point is reached (range I in Figure 9A). Within this region, the slope of $\kappa=f([$ surfactant $])$ is similar to that found in the pre-micellar region with pure surfactant, showing that there is no significant surfactant-polymer effect on the electrical conductivity of the mixture. Above this concentration, a further increase in surfactant concentration leads to a dramatic decrease of the slope of $\kappa=f([$ surfactant $])$ suggesting that polymer-surfactant aggregation occurs and, consequently, the size of the conducting species also increases (range II). ${ }^{30}$ When no free polymer is present in solution (range III, Figure 9A), the addition of further surfactant will make a similar contribution to the increase of the specific conductance to that found in the absence of polymer.

This interaction between polymer and surfactant within surfactant concentration range II is confirmed by emission spectra, where for the same surfactant concentrations a drastic quenching of HTMA-PFP emission, attributed to polymer aggregation, is observed. The decreases in the polyfluorene emission and solution specific conductivity are compatible with neutralization of the polymer positive charge by Coulombic interaction with the negatively charged surfactants, leading to surfactant induced polymer aggregation. As a consequence, the number of ionic species in the system is reduced, drastically diminishing the conductivity.

Moreover, the surfactant concentrations parallel the inflection points of the curves of emission intensity versus surfactant molar concentration, as can be seen in Figure 9B for sodium tetradecyl sulfate.

Since it was found that conductivity changes due to the polymer-surfactant interactions are already rather difficult to observe with decyl surfactants, specific conductivity measurements were not carried out for $n$-alkyl sulfonates with alkyl chains shorter than octyl. For this surfactant, there were no measurable differences between the experiment with and that without polymer in conductivity.

\section{Conclusions}

It has been found that the fluorescence intensity of the cationic conjugated polyelectrolyte HTMA-PFP in 4\% (v/v) DMSOwater mixtures can be modulated through the interaction with even chain length sodium $n$-alkyl sulfonate $\left(\mathrm{C}_{4}-\mathrm{C}_{16}\right)$ or sulfate surfactants. At low surfactant concentrations, a nearly complete quenching of HTMA-PFP emission is observed, while in all of the systems studied, except the butyl, the polymer emission is recovered with surfactant concentrations above their $\mathrm{cmc}$, in some cases reaching values greater than those in the absence of surfactant. No significant differences were observed between surfactants having sulfate and sulfonate head groups.

The polymer-surfactant interactions are believed to involve both electrostatic and hydrophobic contributions. For surfactant concentrations below their cmc's, the neutralization of the polymer charge by the surfactants induces polymer aggregation which leads to the quenching of the polymer fluorescence, an increase in Rayleigh scattering and a decrease in both HTMAPFP absorbance and specific conductivity in solution. HTMAPFP fluorescence quenching follows Stern-Volmer kinetics and mainly involves static contributions. From the changes in the absorption spectra upon addition of surfactant, the absorption spectra of polymer aggregate was determined and found to have a maximum around $402 \mathrm{~nm}$. From these calculations, average aggregation constants were also determined and have values ranging between $4 \times 10^{5}$ and $1 \times 10^{6} \mathrm{~mol}^{-1} \mathrm{~L}$.

Upon increasing surfactant concentration, micelle formation leads to break up of polymer aggregates, as seen through the behavior of the characteristic polyfluorene signals at around $7.8 \mathrm{ppm}$ in the ${ }^{1} \mathrm{H}$ NMR spectra. Micellization leads to the recovery of emission intensity and to a decrease in light scattering. In contrast, no recovery of emission intensity is observed for the butyl sulfonates, suggesting that this not appear to form micelles.

Time-resolved fluorescence experiments show that, depending on the surfactant concentration, the decays at the emission maximum (at $416 \mathrm{~nm}$ ) can be fitted to either biexponential or triexponential kinetics. The longest lifetime (around $460 \mathrm{ps)}$ ) is assigned to the polymer lifetime while the shorter ones (30 and $100 \mathrm{ps}$ ) are attributed to polymer aggregates. The effect of surfactant concentration upon the emission intensity for the longest lifetime component is similar to that obtained in steadystate experiments, decreasing when the emission intensity due to the shortest component increases. The facts that the contributions of the two short-lived components to the emission intensity give a curve, which is complementary to that of the longest one, and have similarities with the behavior of the fluorescence intensity as a function of surfactant concentration are consistent with the presence of two kinds of surfactant-polymer species, tentatively attributed to surfactant induced polymer-polymer aggregates at low surfactant concentrations and surfactantpolymer aggregates (possibly with micellar structures) above the cmc.

In addition, HTMA-PFP would also appear to be a good fluorescent probe for the determination of critical micelle concentrations of $n$-alkylsulfonates and possibly other anionic surfactants.

Acknowledgment. MEC and FEDER are thanked for financial support through the project MAT2004-03827, and POCI/FCT/FEDER through the project POCI/QUI/58291/2004. I.X.G.-Z. also thanks MEC for a research contract through MAT2004-03827 project. M.J.T. thanks Burgos University for financial support of a short stay in Coimbra University. R.E.D.P. thanks FCT for a postdoctoral grant BPD/34558/2007.

Supporting Information Available: Fitting parameters of HTMA-PFP fluorescence decays in DMSO-water and parameters of the linear fitting of the specific conductivity of pure $n$-alkyl sulfonates. This material is available free of charge via the Internet at http://pubs.acs.org.

\section{References and Notes}

(1) (a) Chen, L.; McBranch, D. W.; Wang, H.-L.; Helgeson, R.; Wudl, F.; Whitten, D. G. Proc. Natl. Acad. Sci. U.S.A. 1999, 96, 12287-12292. (b) Chen, L.; Xu, S.; McBranch, D. W.; Whitten, D. J. Am. Chem. Soc. 2000, 122, 9302-9303. (c) Chen, L.; McBranch, D.; Wang, R.; Whitten, D. Chem. Phys. Lett. 2000, 330, 27-33. (d) Abe, S.; Chen. L. J. Polym. Sci., Part B: Polym. Phys. 2003, 41, 1671-1679.

(2) (a) Heeger, P. S.; Heeger, A. J. Proc. Natl. Acad. Sci. 1999, 96, 12219-12221. (b) Wang, D.; Gong, X.; Heeger, P. S.; Rininsland, F.; Bazan, G. C.; Heeger, A. J. Proc. Natl. Acad. Sci. U.S.A. 2002, 99, 49-53. (c) Fan, C.; Plaxco, K. W.; Heeger, A. J. J. Am. Chem. Soc. 2002, 124, $5642-$ 5643. (d) Gaylord, B. S.; Heeger, A. J.; Bazan, G. C. Proc. Natl. Acad Sci. U.S.A. 2002, 99, 10954-10957. (e) Fan, C.; Plaxco, K. W.; Heeger, A. J. Trends Biotechnol. 2005, 23, 186-192.

(3) (a) Liu, B.; Gaylord, B. S.; Wang, S.; Bazan, G. C. J. Am. Chem Soc. 2003, 125, 6705-6714. (b) Liu, B.; Wang, S.; Bazan, G. C.; Mikhailovsky, A. J. Am. Chem. Soc. 2003, 125, 13306-13307. (c) Wang, S.; Liu, B.; Gaylord, B. S.; Bazan, G. C. Adv. Funct. Mater. 2003, 13, 463- 467. (d) Wang, S.; Bazan, G. C. Adv. Mater. 2003, 15, 1425-1428 (e) Dwight, S. J.; Gaylord, B. S.; Hong, J. W.; Bazan, G. C. J. Am. Chem. Soc. 2004, 126, 16850-16859. (f) Wang, S.; Bazan, G. C. Chem. Commun. 2004, 2508-2509. (g) Mallavia, R.; Martinez-Peréz, D.; Chmelka, B. F.; Bazan, G. C. Bol. Soc. Esp. Ceram. V 2004, 43, 327-330. (h) Gaylord, B S.; Massie, M. R.; Feinstein, S. C.; Bazan, G. C. Proc. Natl. Acad. Sci. U.S.A. 2005, 102, 34-39. (i) Liu, B.; Bazan, G. C. J. Am. Chem. Soc. 2006, 128, 1188-1196. (j) Woo, H. Y.; Vak, D.; Korystov, D.; Mikhailovsky, A.; Bazan, G. C.; Kim, D. Y. Adv. Funct. Mater. 2007, 17, 290-295. 
(4) (a) Liu, B.; Bazan, G. C. Chem. Mater. 2004, 16, 4467-4476. (b) Pinto, M. R.; Schanze, K. S. Synthesis-Stuttgart 2002, 9, 1293-1309.

(5) (a) Swager, T. M. Acc. Chem. Res. 1998, 31, 201-207. (b) McQuine, D. J.; Pullen, A. E.; Swager, T. M. Chem. Rev. 2000, 100, 25372574. (c) Juan, Z.; Swager, T. M. Adv. Polym. Sci. 2005, 177, 151-179. (d) Joly, G. D.; Geiger, L.; Kooi, S. E.; Swager, T. M. Macromolecules 2006, 39, 7175-7177.

(6) (a) Tan, C.; Pinto, M. R.; Schanze, K. S. Chem. Commun. 2002, 446-447. (b) DiCesare, N.; Pinto, M. R.; Schanze, K. S.; Lakowicz, J. R. Langmuir 2002, 18, 7785-7787. (c) Tan, C.; Atas, E.; Müller, J. G.; Pinto, M. R.; Kleinman, V. D.; Schanze, K. S. J. Am. Chem. Soc. 2004, 126, 13685-13694. (d) Haskins-Glusac, K.; Pinto, M. R.; Tan, C.; Schanze, K. S. J. Am. Chem. Soc. 2004, 126, 14964-14971. (e) Tan, C. Y.; Pinto, M. R.; Kose, M. E.; Ghiviriga, I.; Schanze, K. S. Adv. Mater. 2004, 16, $1208-$ 1212. (f) Pinto, M. R.; Schanze, K. S. Proc. Natl. Acad. Sci. U.S.A. 2004 101, 7505-7510. (g) Müller, J. G.; Atas, E.; Tan, C.; Schanze, K. S.; Kleiman, V. D. J. Am. Chem. Soc. 2006, 128, 4007-4016.

(7) (a) Lavigne, J. J.; Broughton, D. L.; Wilson, J. N.; Erdogan, B.; Bunz, U. H. F. Macromolecules 2003, 36, 7409-7412. (b) Kim, I.-B.; Dunkhorst, A.; Gilbert, J.; Bunz, U. H. F. Macromolecules 2005, 38, 45604562.

(8) Taira, S.; Yokoyama, K. Biotech. Bioeng. 2004, 88, 35-41.

(9) Ho, H. A.; Boissinot, M.; Bergeron, M. G.; Corbeil, G.; Dore, K.; Boudreau, D.; Leclerc, M. Angew. Chem. Int. Ed. 2002, 41, 15481551.

(10) (a) Xia, C.; Locklin, J.; Youk, J. H.; Fulghum, T.; Advincula, R. C. Langmuir 2002, 18, 955-957. (b) Huang, F.; Wu, H.; Wang, D.; Yang, W.; Cao, Y. Chem. Mater. 2004, 16, 708-716. (c) Huang, F.; Hou, L.; Wu, H.; Wang, X.; Shen, H.; Cao, W.; Yang, W.; Cao, Y. J. Am. Chem. Soc. 2004, 126, 9845-9853. (d) Ma, W.; Iyer, P. K.; Gong, X.; Liu, B.; Moses, D.; Bazan, G. C.; Heeger, A. J. Adv. Mater. 2005, 17, 274-277. (e) Wilson, J. S.; Frampton, M. J.; Michels, J. J.; Sardone, L.; Marletta, G.; Friend, R. H.; Samori, P.; Anderson, H. L.; Cacialli, F. Adv. Mater. 2005, 17, 2659-2663. (f) Dang, T. D.; Bai, S. J.; Heberer, D. P.; Arnold, F. E.; Spry, R. J. J. Polym. Sci., Part B: Polym. Phys. 1993, 31, 1941-1950.

(11) (a) Decher, G. Science 1997, 277, 1232-1237. (b) Baur, J. W.; Kim, S.; Balanda, P. B.; Reynolds, J. R.; Rubner, M. F. Adv. Mater. 1998, 10, 1452-1455. (c) Baur, J. W.; Rubner, M. F.; Reynolds, J. R.; Kim, S. Langmuir 1999, 15, 6460-6469. (d) Fendler, J. H. Chem. Mater. 2001 13, 3196-3210. (e) Kim, D. H.; Hernandez-Lopez, J. L.; Liu, G.; Mihov, G.; Zhi, L.; Bauer, R. E.; Grebel-Köhler, D.; Klapper, M.; Weil, T.; Müllen, K.; Mittler, S.; Knoll, W. Macromol. Chem. Phys. 2005, 206, 52-58.

(12) (a) Sirringhaus, H.; Kawase, T.; Friend, R. H.; Shimoda, T.; Inbasekaran, M.; Wu, W.; Woo, E. P. Science 2000, 290, 2123-2126. (b) de Gans, B.-J.; Duineveld, P. C.; Schubert, U. S. Adv. Mater. 2004, 16, 203-213.

(13) (a) Burrows, H. D.; Lobo, V. M. M.; Pina, J.; Ramos, M. L.; Seixas de Melo, J.; Valente, A. J. M.; Tapia, M. J.; Pradhan, S.; Scherf, U. Macromolecules, 2004, 37, 7425-7427. (b) Tapia, M. J.; Burrows, H. D.; Valente, A. J. M.; Pradhan, S.; Scherf, U.; Lobo, V. M. M.; Pina, J.; Seixas de Melo, J. J. Phys. Chem. B 2005, 109, 19108-19115. (c) Burrows, H. D.; Lobo, V. M. M.; Pina, J.; Ramos, M. L.; Seixas de Melo, J.; Valente,
A. J. M.; Tapia, M. J.; Pradhan, S.; Scherf, U.; Hintschich, S. I.; Rothe, C.; Monkman, A. P. Colloids Surf., A 2005, 270-271, 61-66. (d) Knaapila, M.; Almásy, L.; Garamus, V. M.; Pradhan, S.; Pearson, C.; Petty, M. C.; Scherf, U.; Burrows, H. D.; Monkman, A. P. J. Phys. Chem. B 2006, 110, 10248-10257. (e) Tapia, M. J.; Burrows, H. D.; Knaapila, M.; Monkman, A. P.; Arroyo, A.; Pradhan, S.; Scherf, U.; Pinazo, A.; Pérez, L.; Morán, C. Langmuir, 2006, 22, 10170-10174. (f) Burrows, H. D.; Tapia, M. J.; Silva, C. L.; Pais, A. A. C. C.; Fonseca, S. M.; Pina, J.; Seixas de Melo, J.; Wang, Y.; Marques, E. F.; Knaapila, M.; Monkman, A. P.; Garamus, V. M.; Pradhan, S.; Scherf, U. J. Phys. Chem. B 2007, 111, 4401-4410. (g) Burrows, H. D.; Fonseca, S. M.; Silva, C. L.; Pais, A. A. C. C.; Tapia, M. J.; Pradhan, S.; Scherf, U. J. Chem. Phys., submitted.

(14) (a) Ohmori,Y.; Uchida, M.; Muro, K.; Yoshino, K. Jpn. J. Appl. Phys., Part 2 1991, 30, L1941-L1943. (b) Grice, A. W.; Bradley, D. D. C.; Bernius, M. T.; Inbasekaran, M.; Wu, W. E.; Woo, E. P. Appl. Phys. Lett. 1998, 73, 629-631. (c) Leclerc, M. J. Polym. Sci., Part A: Polym. Chem. 2001, 39, 2867-2873. (d) Scherf, U.; List, E. J. W. Adv. Mater. 2002, 14, 477-487.

(15) Kolishetti, N.; Ramakrishnan, S. J. Chem. Sci. 2007, 119, 185193

(16) Demas, J. N.; Crosby, G. A. J. Phys. Chem. 1971, 75, 991-1024.

(17) Belskii, V. E. Russ. Chem. Bull. 2003, 52, 1347-1352.

(18) Giestas, L.; Yihwa, C.; Lima, J. C.; Vantier-Giongo, C.; Lopes, A.; Maçanita, A. L.; Quina. F. H. J. Phys. Chem. A 2003, 107, 32633269.

(19) Striker, G.; Subramaniam, V.; Seidel, C. A. M.; Volkmer, A. J. J. Phys. Chem. B 1999, 103, 8612-8617.

(20) Vink, H. J. Chem. Soc., Faraday Trans 1 1981, 77, 2439-2449.

(21) Barthel, J.; Feuerlein, F.; Neuder, R.; Wachter, R. J. Sol. Chem. 1980, 9, 209-219.

(22) Stork, M.; Gaylord, B. S.; Heeger, A. J.; Bazan, G. C. Adv. Mater. 2002, 14, 361-366.

(23) International Union of Pure and Applied Chemistry Manual of Symbols and Terminology for Physicochemical Quantitities and Units. Appendix II. Definitions Symbols and Terminology in Colloid and Surface Chemistry, Prepared for publication by Everett, D. H. Pure Appl. Chem. 1972, 31, 577-638; revised internet version, Koopal, L. K., 2001.

(24) Mukerjee, P.; Mysels, K. J. In Critical Micelle Concentrations of Aqueous Surfactants Systems; NBS: Washington, DC, 1971.

(25) Dias, F. B.; Morgado, J.; Maçanita, A. L.; da Costa, F. P.; Burrows, H. D.; Monkman, A. P. Macromolecules 2006, 39, 5854-5864.

(26) López Arbeloa, I. J. Chem. Soc., Faraday Trans. 2 1981, 77, 17251733 .

(27) Ranganathan, R.; Peric, M.; Bales, B. L. J. Phys. Chem. B 1998, $102,8436-8439$.

(28) Kwak, J. C. T., Ed. In Polymer-surfactant systems; Marcel Dekker: New York, 1998; Surfactant Science Series, Vol. 77.

(29) Manne, S.; Cleveland, J. P.; Gaub, H. E.; Stucky, G. D.; Hansma, P. K Langmuir 1994, 10, 4409-4413.

(30) Valente, A. J. M.; Burrows, H. D.; Pereira, R. F.; Ribeiro, A. C. F.; Costa Pereira, J. L. G.; Lobo, V. M. M. Langmuir 2006, 22, 56255629. 